\title{
Improvement of Digital Elevation Model (DEM) using data fusion technique for oil palm replanting phase
}

\begin{abstract}
Digital elevation models (DEMs) play an important role in producing terrain-related applications such as curvature and contour maps for planning and management of oil palm plantation. Data fusion of DEMs derived from terrestrial laser scanning (TLS) and interferometric aperture radar (IfSAR) was developed with the intention to increase the accuracy of IfSAR-derived DEM at a lower cost thus, provide a high-quality data for plantation management. In this research, fusion by weights was carried out after applying regression analysis to integrate both TLS and IfSAR data. The results showed a significant reduction in root mean square error (RMSEs) after fusion. RMSEs of both stations reduced from $1.83 \mathrm{~m}$ to $0.35 \mathrm{~m}$ and from $3.13 \mathrm{~m}$ to $0.41 \mathrm{~m}$ for Station 1 and Station 2, respectively. In addition, data fusion technique for an area with no TLS data were tested around the stations at $200 \mathrm{~m}$ distance. The RMSEs decreased from $2.52 \mathrm{~m}$ to $2.33 \mathrm{~m}$ for Station 1 but the value increased from $2.09 \mathrm{~m}$ to $2.13 \mathrm{~m}$ for Station 2. It was concluded that the proposed fusion technique in the extension area could be done in a relatively flat area but not be used in a steep-slope area.
\end{abstract}

Keyword: Data fusion; TLS; IfSAR; DEM; Oil palm 